\title{
Análisis del feminicidio desde la perspectiva de género y el rol del poder judicial en El Perú
}

\author{
Analysis of feminicide from gender perspective \\ and the role of the Peruvian Judiciary
}

\author{
JANET TELLO GILARDi \\ Jueza de la Corte Suprema de Justicia de la República de \\ Perú. Presidenta de la Comisión Permanente de Acceso \\ a la Justicia de Personas en Condición de Vulnerabilidad \\ y Justicia en tu Comunidad del Poder Judicial del Perú \\ Presidenta de la Asociación Peruana de Mujeres Juezas
}

Recibido: 6/5/2019

Aceptado: 22/10/2019

doi: https://doi.org/10.20318/femeris.2020.5156

\begin{abstract}
Resumen. En el presente trabajo de investigación se realizó un análisis del delito de feminicidio desde la perspectiva de género, a partir del estudio de los criterios judiciales establecidos por las Salas Penal Permanente y Transitorias de la Corte Suprema de Justicia de la República de Perú, para determinar su concordancia con las disposiciones de los tratados e instrumentos internacionales de protección de los derechos fundamentales de la mujer y los estándares determinados por la Corte Interamericana y la Corte Europea de Derechos Humanos. Para su desarrollo, se revisó la jurisprudencia nacional e internacional. Además, se consideró la doctrina y la legislación interna y comparada con otros países vanguardistas que enfrentan la discriminación y la violencia contra las niñas, adolescentes, mujeres jóvenes y adultas mayores por motivos de género, orientación sexual o identidad de género, para efectivizar el acceso a la justicia de este grupo en condición de vulnerabilidad. En cuanto a la metodología de investigación esta es descriptiva, debido a que se desarrollan los conceptos y clasificaciones de las instituciones jurídicas abordadas en este trabajo. Asimismo, se muestra la realidad problemática del feminicidio en el Perú, la cual es contrastada con los fallos judiciales. Para finalmente, presentar las conclusiones de la investigadora.

Palabras clave: Feminicidio, perspectiva de género, discriminación y violencia de género, acceso a la justicia, persona en condición de vulnerabilidad .
\end{abstract}

Abstract. This research paper analyzes the crime of femicide from a gender perspective, based on the study of judicial criteria established by the Permanent and Transitory Criminal Chambers of the Supreme Court of Justice of the Republic of Peru, in order to determine its concordance with the provisions of treaties and international instruments for the protection of the fundamental rights of women and the standards determined by the Inter-American Court and the European Court of Human Rights. The research undertook included a review of national and international jurisprudence. It also considered doctrine and domestic and comparative legislation with other avant-garde countries that face discrimination and violence against girls,

*janetellog@yahoo.es 
adolescents, young women, and older adult women due to gender, sexual orientation or gender identity, in order to make access to justice of this vulnerable group effective. The research methodology used is descriptive, since concepts and classifications of the legal institutions discussed in this paper are developed. Moreover, the problematic reality of femicide in Peru is shown and is contrasted with judicial decisions. Finally, it presents the conclusions of the researcher.

Keywords: Femicide, feminicide, gender perspective, gender discrimination and violence, access to justice, vulnerable person.

\section{Introducción}

Las desigualdades de género en el Perú, como en los demás países del mundo, se encuentran tan arraigadas en las estructuras sociales patriarcales, que conseguir la ansiada vida libre de violencia y la igualdad, parece aún una realidad lejana.

La violencia contra las niñas, adolescentes, mujeres jóvenes y adultas mayores continúa y, en miles de casos, termina en su expresión extrema: la muerte.

Según el Ministerio de la Mujer y Poblaciones Vulnerables, en el 2017, se registraron 121 casos de feminicidio. Mientras que, en el 2018, fueron 149 las mujeres víctimas de feminicidio.

El incremento de estas cifras es impresionante. Pero, más sorprendente es que en el año 2019, fueron 168 el número de mujeres asesinadas en todo el país, cifra récord en la última década, de acuerdo a los datos del Ministerio de la Mujer y Poblaciones Vulnerables, registrándose a las dos primeras víctimas de feminicidio el primer día del mes de enero. Asimismo, el 8 de marzo, durante las conmemoraciones por el Día Internacional de la Mujer, los medios de comunicación dieron a conocer la muerte de una madre y su bebé, a manos de su ex pareja. Días después, la prensa informaba otro horrendo crimen contra una joven mujer, quien fue descuartizada en una de las provincias más pobres del país.

Estos alarmantes datos confirman la preocupante situación que afrontan a diario las mujeres peruanas frente a la discriminación y la violencia.

Esta muerte violenta por razones de género, se ha tipificado como el delito de femicidio o feminicidio en la mayoría de las legislaciones de nuestra región.

En el Perú, el delito de feminicidio se reguló a través de la modificación del artículo 107 del Código Penal, por la Ley $\mathrm{N}^{\circ} 29819$, del 27 de diciembre de 2011, pero que solo sancionó el feminicidio íntimo. Más adelante, se aprobó la Ley $\mathrm{N}^{\circ} 30068$, que incorporó el artículo 108-B al Código Penal, el 18 de julio de 2013, como la muerte de una mujer, por el hecho de serlo, en contextos de hostigamiento sexual, violencia familiar, abuso de poder y discriminación de género. Es decir, el feminicidio se convirtió en un delito autónomo.

Años más tarde, para enfrentar esta problemática, se promulgó la Ley para Prevenir, Sancionar y Erradicar la Violencia contra las Mujeres y los Integrantes del Grupo Familiar, Ley $\mathrm{N}^{\circ} 30364$, publicada el 23 de noviembre de 2015, que estableció mecanismos, medidas y políticas integrales de prevención, atención y protección de las víctimas, así como reparación del daño causado; y dispuso la persecución, sanción y reeducación de los agresores sentenciados con el fin de garantizar a las mujeres y al grupo familiar una vida libre de violencia, asegurando el ejercicio pleno de sus derechos fundamentales. Asi- 
mismo, se publicó el Reglamento de la Ley N³0364, mediante el Decreto Supremo N0092016-MIMP, del 27 de julio de 2016.

De otro lado, se aprobó el Plan Nacional Contra la Violencia de Género 2016-2021, a

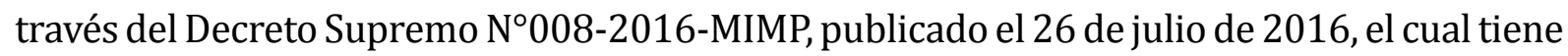
como primer objetivo estratégico cambiar los patrones socioculturales que reproducen relaciones desiguales de poder y diferencias jerárquicas que legitiman y exacerban la violencia de género, que afecta desproporcionadamente a las mujeres en su diversidad, a fin de lograr de disminución de los feminicidios. En igual sentido, se promulgó la Política Nacional de Igualdad de Género, el 4 de abril de 2019, por el Decreto Supremo N008-2019-MIMP.

Todos estos instrumentos fueron reforzados con el Decreto Legislativo que Fortalece la Lucha contra el Feminicidio, la Violencia Familiar y la Violencia de Género, Decreto Legislativo $\mathrm{N}^{\circ} 1323$, publicado el 6 de enero de 2017, que modificó el artículo 108-B del Código Penal, la figura típica del feminicidio, como el asesinato de una mujer en cualquier contexto de discriminación, independientemente de que exista o haya existido una relación conyugal o de convivencia entre la víctima con el feminicida; y también reguló sus formas agravantes por razones de la edad, la discapacidad y otras causas de vulnerabilidad.

Todo lo anterior se realizó en cumplimiento de lo dispuesto por la Convención para la Eliminación de todas las Formas de Discriminación contra la Mujer y la Convención Interamericana para Prevenir, Sancionar y Erradicar la Violencia contra la Mujer. Tratados que el Estado peruano ha ratificado y que forman parte de la legislación nacional.

Aunque se ha avanzado bastante en la regulación del delito de feminicidio, tanto que se han eliminado los beneficios procesales que generaban impunidad y flexibilizaban la sanción a los feminicidas, desde la magistratura, se debe continuar con nuestra labor para cambiar los estereotipos socioculturales discriminatorios por razón de género que se perpetúan en la sociedad machista.

En tal sentido, las juezas y los jueces deben cumplir con las obligaciones internacionales de protección de los derechos fundamentales, actuando con la debida diligencia en los casos de feminicidio, dictando sentencias ejemplares, que incorporen la perspectiva de género, para lograr la ansiada vida libre de violencia y la igualdad en nuestro país.

A lo largo de este trabajo se desarrollará este tema, a través del análisis de las normas y la doctrina, así como del estudio de la jurisprudencia nacional y del sistema interamericano y europeo.

\section{Marco histórico y legal para una justicia sin discriminación por género}

\subsection{Protección constitucional}

La Constitución Política del Perú de 1993, señala en su artículo 2.2 que todas las personas tienen derecho a la igualdad ante la ley y que nadie debe ser discriminado por ningún motivo, sea esto por razón de su origen, raza, sexo, idioma, religión, opinión, condición económica o de cualquier otra índole, como la orientación sexual o la identidad de género. 
Esta disposición tiene como antecedente lo señalado en la Declaración Universal de Derechos Humanos, del 10 de diciembre de 1948, el cual manifiesta una interpretación de reconocimiento de los derechos y libertades, de hombres y mujeres, en igualdad de condiciones. Bajo esta premisa, también fue concebida la Convención Interamericana sobre Concesión de los Derechos Civiles a la Mujer, aprobada por la Organización de Estados Americanos en ese mismo año, reafirmando así el principio de la igualdad de derechos humanos contenido en la Carta de las Naciones Unidas. No obstante, es a través de la aprobación de la Convención sobre los Derechos Políticos de la Mujer, del 20 de diciembre de 1952, que la condición jurídica, política y social de las mujeres recibe una mayor atención para la protección de sus derechos fundamentales.

Más adelante, se reconocería la igualdad de sus derechos civiles, económicos, sociales y culturales en el Pacto Internacional de Derechos Económicos, Sociales y Culturales, del 16 de diciembre de 1966, y en la Convención Americana sobre Derechos Humanos, del 22 de noviembre de 1969, también conocido como el "Pacto de San José" de Costa Rica.

Pese a todo ello, las mujeres continuaban siendo objeto de discriminaciones y víctimas de diversas formas de violencia, que vulneraban los principios de la igualdad de derechos y del respeto de la dignidad humana.

\subsection{La Convención CEDAW}

El 18 de diciembre de 1979, se aprobó la Convención sobre la Eliminación de Todas las Formas de Discriminación contra la Mujer (CEDAW), por la Asamblea General de las Naciones Unidas que creó todo un nuevo marco jurídico que adoptó las medidas necesarias a fin de suprimir esta discriminación en todas sus formas y manifestaciones en contra de los derechos humanos y la condición personal de las mujeres en todas las etapas de su vida.

Es decir, la CEDAW estableció un cambio de paradigma que enfrentó toda distinción, exclusión o restricción, basada en el género, que tenga por objeto o por resultado menoscabar o anular el reconocimiento, goce o ejercicio por la mujer, independientemente de su estado civil, sobre la base de la igualdad con el hombre, de los derechos humanos y las libertades fundamentales en las esferas política, económica, social, cultural y civil o en cualquier otra esfera, de acuerdo a lo señalado en su primer artículo.

Según Nieves Rico (1996; p.11), quien fuera Consultora de la Unidad Mujer y Desarrollo de la Comisión Económica para América Latina y el Caribe (CEPAL), expone que:

[E]n dicho instrumento sólo se aborda en forma tangencial el problema de la violencia contra las mujeres; una de sus deficiencias es precisamente la falta de una definición clara de la violencia de género. La preocupación específica por este problema comenzó a manifestarse a partir de 1980, cuando en la Conferencia Mundial del Decenio de las Naciones Unidas para la Mujer celebrada en Copenhague se adoptó la resolución titulada "La mujer maltratada y la violencia en la familia. 
El Perú, mediante la Resolución Legislativa N²3432, aprobó la incorporación a la Convención para la Eliminación de Todas las Formas de Discriminación contra la Mujer, el 5 de junio de 1982, y lo ratificó el 13 de septiembre de ese mismo año, comprometiéndose a garantizar el cumplimiento de este tratado en todo el país.

Casi 15 años después, desde la entrada en vigor de la CEDAW, la Asamblea General de las Naciones Unidas decretó la Declaración sobre la Eliminación de la Violencia Contra la Mujer, el 20 de diciembre de 1993, la cual reconoció que la violencia contra las mujeres constituye una manifestación de relaciones de poder históricamente desiguales con el hombre, que la colocan en una situación de subordinación. Y, que los Estados tienen la obligación de condenar toda forma de violencia y no invocar ninguna costumbre, tradición o consideración religiosa para eludir su responsabilidad que procure eliminarla. Así como, el deber de proceder con la debida diligencia a fin de prevenir, investigar y castigar todo acto de violencia contra la mujer, conforme a lo indicado en su artículo cuarto.

\subsection{La Convención de Belém do Pará}

La Organización de Estados Americanos aprobó la Convención Interamericana para Prevenir, Sancionar y Erradicar la Violencia Contra la Mujer, conocido como la "Convención de Belém do Pará", del 9 de junio de 1994, la cual desarrolla en su preámbulo que la eliminación de la violencia contra la mujer es una condición indispensable para su desarrollo individual y social y su plena e igualitaria participación en todas las esferas de vida. En su artículo primero, desarrolla una aproximación inicial sobre el concepto de la violencia de género. Asimismo, autoriza a las personas a presentar peticiones ante la Comisión Interamericana de Derechos Humanos, denunciando la violación de sus principales garantías, y permite a los Estados partes y a la Comisión Interamericana de Mujeres a solicitar que la Corte Interamericana de Derechos Humanos emita opiniones consultivas sobre la interpretación de la Convención.

En tal sentido, la Convención de Belém do Pará estableció mecanismos interamericanos de protección, a partir de lo dispuesto en su Capítulo IV, y a cargo del Mecanismo de Seguimiento de la Convención de Belém do Pará (MESECVI) a través de los informes nacionales emitidos por los países, de forma periódica. Por ejemplo, es importante destacar la Recomendación General $N^{\circ} 1$ del Comité de Expertas del MESECVI sobre la legítima defensa, la necesidad racional del medio empleado para repelar la agresión y la violencia contra las mujeres, de acuerdo con el artículo 2 de la Convención, emitida el 5 de diciembre de 2018, para la prevención y sanción de la violencia de género y el feminicidio.

De igual forma, debe destacarse que la Convención de Belém do Pará, admite que la mujer o el grupo de mujeres que han sufrido la violación de sus derechos fundamentales puedan acceder ante un organismo jurisdiccional internacional para su asistencia, investigación, sanción de los agentes responsables y reparación del daño por el derecho vulnerado. 
Para Luz Patricia Mejía Guerrero (2012; pp.195-196), quien fue Comisionada de la Comisión Interamericana de Derechos Humanos y Relatora para los Derechos de las Mujeres, sostiene que:

[D]urante años los derechos humanos de niñas, adolescentes y mujeres en ámbitos diferentes a sus relaciones con el Estado, no fueron reconocidos como derechos humanos, toda vez que todo aquello que ocurriese en el espacio privado era considerado como competencia de otras ramas del derecho, y que le competía al derecho de familia o al derecho civil regularlo en tanto y en cuanto eran relaciones entre particulares. Así, la Convención de Belém do Pará pone bajo la lupa del Derecho Internacional de los Derechos Humanos la realidad que enfrentan las mujeres a diario en la Región, adoptando como nuevo paradigma de los derechos humanos -y en especial de los derechos humanos de las mujeres- que lo privado es público y, en consecuencia, le corresponde a los Estados asumir el deber indelegable de prevenir, erradicar y sancionar los hechos de violencia en la vida de las mujeres, tanto en las esferas públicas como en las esferas privadas.

El Estado peruano se incorporó a la Convención de Belém do Pará, a través de la Resolución Legislativa $\mathrm{N}^{\circ} 26583$, del 22 de marzo de 1996, y lo ratificó el 4 de abril de ese mismo año.

\subsection{El Informe de la Cuarta Conferencia Mundial sobre la Mujer}

El Informe de la Cuarta Conferencia Mundial sobre la Mujer de las Naciones Unidas (1995; p.51), realizada en Beijing, del 4 al 15 de septiembre de 1995, indicó que:

112. La violencia contra la mujer impide el logro de los objetivos de igualdad, desarrollo y paz. La violencia contra la mujer viola y menoscaba o impide su disfrute de los derechos humanos y las libertades fundamentales. La inveterada incapacidad de proteger y promover esos derechos y libertades en los casos de violencia contra la mujer es un problema que incumbe a todos los Estados y exige que se adopten medidas al respecto. Desde la Conferencia de Nairobi se ha ampliado considerablemente el conocimiento de las causas, las consecuencias y el alcance de esa violencia, así como las medidas encaminadas a ponerle fin. En todas las sociedades, en mayor o menor medida, las mujeres y las niñas están sujetas a malos tratos de índole física, sexual y psicológica, sin distinción en cuanto a su nivel de ingresos, clase y cultura. La baja condición social y económica de la mujer puede ser tanto una causa como una consecuencia de la violencia de que es víctima.

Por tal motivo, no se puede hablar de una justicia sin discriminación, cuando, en la realidad, a la persona que se le reconoce un derecho no puede ejercerlo libremente ni tampoco acceder a los servicios judiciales para restituir la vulneración de este, encontrándose así en una situación de vulnerabilidad y, mayor aun, cuando se es mujer, debiendo enfrentarse a una sociedad machista que históricamente la ha discriminado y violentado. 


\subsection{Las Reglas de Brasilia}

En la XIV Edición de la Cumbre Judicial Iberoamericana, llevada a cabo en Brasil, del 4 al 6 de marzo de 2008, se elaboraron unas Reglas Básicas relativas al acceso a la justicia de las personas que se encuentran en condición de vulnerabilidad, desarrolladas en base a los principios recogidos en la Carta de Derechos de las Personas ante la Justicia en el Espacio Judicial Iberoamericano, concebida en la VII Edición de la Cumbre, en México, del 27 al 29 de noviembre de 2002, específicamente los que se incluyen en la parte titulada "Una justicia que protege a los más débiles".

Es así que nacen las 100 Reglas de Brasilia, cuyo objetivo es promover el efectivo acceso a la justicia para la defensa de los derechos de las personas en condición de vulnerabilidad que, por razón de su edad, género, estado físico o mental, o por circunstancias sociales, económicas, étnicas y/o culturales, encuentran especiales dificultades para ejercitar con plenitud ante el sistema de justicia los derechos reconocidos por el ordenamiento jurídico, conforme lo señala la Regla de Brasilia $\mathrm{N}^{\circ} 3$. Así como, establecer recomendaciones para quienes prestan sus servicios en el sistema judicial.

No solamente se refieren a la promoción de políticas públicas que garanticen el acceso a la justicia de estas personas, sino también al trabajo cotidiano de todos los servidores y operadores del sistema judicial y quienes intervienen de una u otra forma en su funcionamiento. De lo que se trata, es que el propio sistema de justicia contribuya a la reducción de las desigualdades sociales, actuando más intensamente para vencer, eliminar o mitigar las barreras o limitaciones.

La Regla de Brasilia $N^{\circ} 17$ indica que la discriminación que la mujer sufre en determinados ámbitos supone un obstáculo para el acceso a la justicia, que se ve agravado en aquellos casos en los que concurra alguna otra causa de vulnerabilidad. Asimismo, la Regla de Brasilia $\mathrm{N}^{\circ} 19$, considera que la violencia contra la mujer es cualquier acción o conducta, basada en su género, que cause muerte, daño o sufrimiento físico, sexual o psicológico a la mujer, tanto en el ámbito público como en el privado, mediante el empleo de la violencia física o psíquica.

Cabe resaltar que, la Regla de Brasilia $\mathrm{N}^{\circ} 20$, desarrolla una serie de recomendaciones a los Estados, señalando que:

[Deben impulsar] las medidas necesarias para eliminar la discriminación contra la mujer en el acceso al sistema de justicia para la tutela de sus derechos e intereses legítimos, logrando la igualdad efectiva de condiciones.

[Deben prestar] una especial atención en los supuestos de violencia contra la mujer, estableciendo mecanismos eficaces destinados a la protección de sus bienes jurídicos, al acceso a los procesos judiciales y a su tramitación ágil y oportuna.

Como consecuencia de la promulgación de este instrumento internacional, al cual el Poder Judicial del Perú se adhirió en el 2010, la Asamblea Plenaria de la XVII Edición de la Cumbre Judicial Iberoamericana, realizado en Chile, en 2014, aprobó el Protocolo 
Iberoamericano para el acceso a la justicia de las personas y grupos en condiciones de vulnerabilidad, con especial énfasis en la justicia de género.

El objetivo del Protocolo de Actuación Judicial para casos de Violencia de Género contra las Mujeres, es dotar de herramientas prácticas a las y los jueces para garantizar el acceso real a la justicia para las mujeres y la protección de la vida, libertad e integridad, con el fin de que las mujeres del mundo vivan una vida libre de violencia, y ejerzan plenamente sus derechos, aplicando también el enfoque de derechos humanos en los procesos judiciales.

\section{Perspectiva de género en la administración de justicia}

\subsection{Conceptualización de la perspectiva de género}

Para Joan W. Scott (1986), el género es una forma primaria de relaciones significantes de poder, es un elemento constitutivo de las relaciones basadas en las diferencias que distinguen a los sexos, en la forma que las identidades masculinas y femeninas se encuentran determinadas por los procesos diferenciados de socialización, por lo que no son simples derivaciones de las diferencias biológicas, sino complejas construcciones sociales cargadas de significación que se proyectan y activan a través de las diversas estructuras regulatorias de la sociedad.

De igual manera, Marcela Huaita Alegre (2009; p.17) sostiene que:

La perspectiva o enfoque de género es un marco de análisis teórico y conceptual que permite detectar los factores de desigualdad que afectan a hombres y mujeres en los diferentes ámbitos de la vida humana. Ello permite diferenciar entre la condición y posición de las mujeres respecto de los hombres. En ese sentido, la condición de vida se refiere a la esfera inmediata de la experiencia de cada persona (...) y la posición en la sociedad, que más bien está referida al nivel social y económico de las mismas (...) Asimismo, permite planificar acciones que permitan modificar las estructuras en las que se fundan las desigualdades y que las hacen permanentes.

En este sentido, la perspectiva de género es un mecanismo de análisis que busca explicar el fenómeno de la desigualdad y de la inequidad entre hombres y mujeres. Esta figura se erige como una categoría analítica en la creación e interpretación jurídica, llamada a garantizar el principio de igualdad (Jiménez; 2017; p.4).

\subsection{Perspectiva de género en los países de Iberoamérica}

Argentina y México han sido los países pioneros de esta región que han promovido la igualdad de género, a través de los movimientos feministas, debido a las altas estadísticas de casos de violencia de género y de feminicidio, como consecuencia de sus realidades políticas y sociales. No se deben olvidar los casos de asesinato contra mujeres ocurrido en la ciudad de Juárez. 
Por ejemplo, el Poder Judicial del Estado de Chiapas promulgó los Lineamientos de Equidad de Género y Derechos Humanos, aprobado por el Consejo de la Judicatura del Poder Judicial, el 19 de septiembre de 2012. Asimismo, ese mismo año, el Poder Judicial del Estado de Tabasco publicó el Manual de Equidad de Género. Más adelante, la Suprema Corte de Justicia de la Nación aprobó el Protocolo para Juzgar con Perspectiva de Género: Haciendo realidad el derecho a la igualdad, en el 2013.

En Centroamérica, el Poder Judicial de Costa Rica incorporó la perspectiva de género dentro de su política de igualdad, aprobada por la Corte Plena, el 7 de noviembre de 2005. De igual manera, el enfoque de género fue aprobado mediante la Resolución N³041-201, el 1 de noviembre de 2007, por el Pleno de la Suprema Corte de Justicia del Poder Judicial de República Dominicana.

Y en España se promulgó la Ley Orgánica 3/2007, del 23 de marzo de 2007, para la igualdad efectiva de mujeres y hombres, abordando la problemática de la desigualdad bajo un enfoque de género dentro de la administración de justicia, creándose la Comisión de Igualdad del Consejo General del Poder Judicial y se aprobó el Plan de Igualdad de la Carrera Judicial, del 14 de febrero de 2013.

\subsection{El sistema de justicia peruano}

La potestad de administrar justicia se ejerce a través de las juezas y jueces del Poder Judicial, de acuerdo con lo establecido en el artículo 138 de la Constitución Política. Asimismo, esta función jurisdiccional debe realizarse de forma independiente e imparcial, en observancia con el debido proceso, para una tutela judicial eficaz, conforme lo indica el artículo 139.3 de la Carta Magna.

Estas garantías judiciales para la protección de los derechos fundamentales de todas las personas, tiene como fuente el artículo 8 de la Convención Americana sobre Derechos Humanos, como un primer paso para efectivizar el acceso a la justicia, en igualdad de condiciones, para hombres y mujeres. De igual forma, el artículo 2 de la CEDAW estableció los inicios para la implementación de la perspectiva de género, que posteriormente formarían parte de las legislaciones internas de cada país, al encaminar una política para eliminar la discriminación contra la mujer, reforzada con las disposiciones establecidas en la Convención de Belém do Pará, para efectivizar su acceso a la justicia.

Sin embargo, es importante señalar que existe, todavía, una disparidad entre el número de juezas y jueces que forman parte del sistema de administración de justicia. En el Perú, esto se observa en el máximo órgano de justicia del país, la Corte Suprema de Justicia de la República, que de los 18 jueces supremos titulares, solo 4 son mujeres. De otro lado, en el 2017, según las cifras del Poder Judicial, había un total de 3071 magistrados, de los cuales 1218 son mujeres, es decir, menos de la mitad. Entonces, se evidencia que existe un mayor número de jueces que administran justicia, pero que con las políticas institucionales se quiere cambiar esta realidad, dejando atrás esta estructura social machista, aplicando el enfoque de género. 


\subsection{Perspectiva de género en la administración de justicia peruana}

\subsubsection{Políticas institucionales}

La promulgación de la Ley para Prevenir, Sancionar y Erradicar la Violencia contra las Mujeres y los Integrantes del Grupo Familiar, Ley ํ30364, permitió profundizar la aplicación de la perspectiva de género en el Poder Judicial, creándose la Comisión de Justicia de Género y el Programa para la Implementación de la Ley $\mathrm{N}^{\circ} 30364$, para la coordinación intra e interinstitucional.

Además, se aprobó el Plan Nacional de Acceso a la Justicia de Personas en Condición de Vulnerabilidad 2016-2021, mediante la Resolución Administrativa №090-2016-CE-PJ, el 7 de abril de 2016, para la eficacia de las 100 Reglas de Brasilia, a las cuales este Poder del Estado se adhirió por la Resolución Administrativa N²66-2010-CE-PJ. Su ejecución y monitoreo se encuentra a cargo de la Comisión Permanente de Acceso a la Justicia de Personas en Condición de Vulnerabilidad y Justicia en tu Comunidad.

El plan nacional tiene como objetivos del Eje N8: Género, la prevención y la erradicación de la discriminación y la violencia por razón de género aplicando los enfoques de interculturalidad y de derechos humanos.

Desde el Consejo Ejecutivo del Poder Judicial también se aprobaron los Lineamientos Técnicos para la Transversalización del Enfoque de Género en la Gestión Institucional del Poder Judicial, mediante la Resolución Administrativa Nº07-2018-CE-PJ, del 10 de enero de 2018. Además, del Circular que establece como política institucional la prioridad y celeridad en el trámite de los procesos judiciales en materia de delitos de violación sexual, violencia familiar y feminicidio, a través de la Resolución Administrativa $\mathrm{N}^{\circ} 302$ 2018-P-PJ, del 16 de agosto de 2018.

Cabe resaltar que, a partir de estas políticas institucionales, se crearon los Módulos Judiciales Integrados en Violencia contra las Mujeres e Integrantes, en los en los Distritos Judiciales de Arequipa, Cusco, Junín, Lambayeque, La Libertad, Lima Este, Lima Norte y Lima Sur. Los cuales se quieren ampliar a nivel nacional.

\subsubsection{Criterios jurisdiccionales}

La perspectiva de género también fue implementada, a través del Acuerdo Plenario $^{1} \mathrm{~N}^{\circ} 1-2011 / \mathrm{CJ}-116$, sobre la apreciación de la prueba en los delitos contra la libertad sexual, del 6 de diciembre de 2012, establecido como doctrina legal por las Salas Penales Permanente y Transitoria de la Corte Suprema de Justicia. Asimismo, en el Acuerdo Plenario $\mathrm{N}^{\circ} 3-2011 / \mathrm{CJ}-116$, sobre las diferencias típicas y penalidad en los delitos contra la libertad sexual y la trata de personas, del 6 de diciembre de 2011.

\footnotetext{
${ }^{1}$ Emitido por los Jueces Supremos de determinada especialidad respecto a algún tema de conflictividad en la jurisprudencia nacional, cuyo objetivo principal es un mejor desarrollo y uniformidad de los criterios jurisprudenciales adoptados y que son de obligatoria aplicación por todos los jueces del país.
} 
Años más tarde, la Corte Suprema de Justicia estableció el Acuerdo Plenario $\mathrm{N}^{\circ} 1$ 2015/CJ-116, sobre la aplicación judicial del artículo 15 del Código Penal y los procesos interculturales por delitos de violación sexual, del 2 de octubre de 2015, que aplicó el enfoque de género, el interés superior del niño y la condición de la vulnerabilidad de mujeres, niñas y adolescentes en contextos pluriculturales. Y, en el Acuerdo Plenario $\mathrm{N}^{\circ} 5$ 2016/CJ-116, del 12 de junio de 2017, sobre los delitos de violencia contra la mujer y los integrantes del grupo familiar, respecto al ámbito procesal de la Ley $\mathrm{N}^{\circ} 30364$.

Especialmente, en el Acuerdo Plenario N001-2016/CJ-116, las Salas Penal Permanente y Transitorias de la Corte Suprema de Justicia establecieron criterios judiciales que deben ser aplicados en los casos de feminicidio, incorporando la perspectiva de género. Este Acuerdo advierte que el feminicidio no se trata de un hecho aislado, sino que responde a una lógica social de estereotipos y roles de género, que discriminan a las mujeres.

Posteriormente, también estaría enunciada en las Sentencias Plenarias Casatorias N¹-2018/CIJ-433, del 18 de diciembre de 2018, sobre los alcances de la determinación de la pena en los delitos sexuales; y $\mathrm{N}^{\circ} 2-2018 / \mathrm{CIJ}-433$, de la misma fecha, respecto del examen de ADN en el ámbito procesal penal, en particular en los delitos sexuales.

\subsection{Asociaciones de juezas y jueces en el Perú}

Se debe destacar la participación de las asociaciones de juezas y jueces, quienes trabajan desde hace varios años, incorporando la perspectiva de género para juzgar en igualdad de condiciones y sin discriminación de ningún tipo, así como apoyar de forma incesante y ardua a las personas en condición de vulnerabilidad. Como es el caso de la Asociación de Jueces para la Justicia y Democracia (JUSDEM) a través del Capítulo de Mujeres Juezas, quienes mediante su propia experiencia, se trasladan a aquellas zonas marginales y pobres del país, para brindar orientación legal gratuita y realizar campañas de promoción de derechos, así como presentar reformas legislativas que le hagan frente a la violencia de género, para la protección de los derechos de las mujeres, promoviendo la aplicación de mecanismos judiciales con enfoque de género. En la misma línea, desarrolla sus actividades la Asociación Peruana de Mujeres Juezas (APMJ), la cual se constituyó formalmente en el 2016, como la continuación del Capítulo de Mujeres Juezas de JUSDEM, para afiliarse a la International Association of Women Judges (IAWJ).

\section{Estereotipos, discriminación y violencia basada en género}

\subsection{Conceptualización de los estereotipos de género}

Los estereotipos se pueden definir como aquella visión generalizada o popular sobre los atributos y roles que caracterizan a ciertas personas integrantes de un grupo social. El concepto de "estereotipo" mantiene una vinculación muy estrecha con las nociones de 
"prejuicio", como aquella creencia de carácter negativa sobre ese grupo social y de "discriminación" como la conducta de falta de igualdad en el tratamiento a las personas de aquel grupo sobre el que existe cierto prejuicio (González; 1999; pp.79-80). Históricamente, esto ha venido sucediendo entre los hombres y las mujeres, llegando a crearse estereotipos de género sobre lo que es "masculino" y lo que es "femenino".

Rebecca J. Cook y Simone Cusack (2010; p.23), exponen que:

"Estereotipo de género" es un término general que se refiere a "un grupo estructurado de creencias sobre los atributos personales de mujeres y hombres". Dichas creencias pueden implicar una variedad de componentes incluyendo características de la personalidad, comportamientos y roles, características físicas y apariencia u ocupaciones y presunciones sobre la orientación sexual. Un estereotipo personal refleja las creencias propias de un individuo sobre un grupo objeto o sobre el sujeto del estereotipo, mientras que un estereotipo cultural o colectivo refleja una creencia ampliamente compartida sobre un grupo objeto o sobre el sujeto de un estereotipo. Los componentes de los estereotipos de género evolucionan y varían de acuerdo con los diferentes contextos.

En ese sentido, a lo largo de los años, se mantuvo la falsa creencia de superioridad del hombre sobre la mujer, quien debía mantener una conducta sumisa frente al varón. Lo que trajo como consecuencia la vulneración de los derechos fundamentales de la mujer, de forma directa, a través de las agresiones físicas, psicológicas, sexuales, económicas o patrimoniales, la trata y el feminicidio.

La violencia contra las mujeres además de ser una violación de sus derechos humanos, afecta su dignidad y no tiene límites geográficos, culturales o económicos.

Perjudica a las familias, a las comunidades y a la sociedad durante generaciones. Empobrece a las mujeres, disminuye la productividad económica de las naciones, agota los recursos de los servicios públicos y reduce la formación de capital humano.

De otro lado, debo resaltar que la mujer también sufre la vulneración de sus derechos de manera indirecta, mediante la designación de roles dentro del grupo familiar y en la sociedad, el uso del lenguaje y la publicidad sexista en los medios de comunicación, así como la falta de acceso a la educación, la cultura, al trabajo, a la salud, la política, entre muchos otros ejemplos.

En este contexto, los estereotipos de género generan un ciclo vicioso en el cual las sociedades permiten que los prejuicios injustos sobre las mujeres se asienten, causando una mayor devaluación de la mujer. Asimismo, las sociedades no reconocen ni eliminan tales prejuicios ni los estereotipos asociados, exacerbando un clima de impunidad de las violaciones de los derechos fundamentales de las mujeres (Cook y Cusack; 2010).

\subsection{Discriminación y violencia de género}

En el Perú, según los datos del Ministerio de la Mujer y Poblaciones, que en el 2017 registraron 81,009 casos de violencia familiar y/o sexual. Y que, en el 2018, esta cifra se 
elevó a 114,182 mujeres víctimas de violencia de género. Mientras que, en el 2019, este número llegó a los 181,885 casos y sigue en aumento de forma alarmante.

No obstante, se puede afirmar que existen "cifras ocultas", debido a que no todas las mujeres denuncian los hechos de violencia por miedo, vergüenza, esperanza de lograr un cambio en el agresor, dificultades económicas, falta de información o lo que es peor, la naturalización de la violencia de género.

En nuestro país, lo paradigmático de esta situación es que la estructura social machista peruana, continúa invisibilizando e incluso justifica la discriminación y la violencia contra la mujer.

Por tal motivo, los tratados e instrumentos internacionales de protección de los derechos humanos han establecido obligaciones a los países, para modificar los patrones socioculturales de conducta de hombres y mujeres, con miras a alcanzar la eliminación de los prejuicios y las prácticas consuetudinarias y de cualquier otra índole que estén basados en la idea de la inferioridad o superioridad de cualquiera de los sexos o en funciones estereotipadas de hombres y mujeres, conforme lo señala el artículo 5 de la Convención CEDAW.

De igual forma, el Comité para la Eliminación de la Discriminación contra la Mujer, a través de la Recomendación General N35, sobre la violencia por razón de género contra la mujer, del 26 de julio de 2017, que actualiza la Recomendación General N¹9, del 29 de enero de 1992, considera, en su décimo párrafo, que la violencia por razón de género es uno de los medios sociales, políticos y económicos fundamentales a través de los cuales se perpetúa la posición subordinada de la mujer con respecto al hombre y sus papeles estereotipados; lo que constituye un grave obstáculo para el logro de la igualdad sustantiva entre mujeres y hombres, para el disfrute pleno de los derechos humanos y libertades fundamentales de la mujer, que por largo tiempo le fue negado.

\subsubsection{Jurisprudencia interamericana}

Se han desarrollado estándares para la igualdad de género frente a la intersección de distintas formas de discriminación contra las mujeres. La Corte Interamericana de Derechos Humanos, en el Caso Atala Riffo y Niñas vs Chile, a través de la sentencia del 24 de febrero de 2012, resolvió sancionar al Estado chileno por el trato discriminatoria que sufrió Karen Atala, debido a su orientación sexual, en el proceso judicial que resultó en el retiro del cuidado y custodia de sus hijas M., V. y R., al interferirse arbitrariamente en su vida privada y familiar.

Por su parte, la Comisión Interamericana de Derechos Humanos desarrolló la vinculación de la discriminación y la violencia contra las mujeres. En el Caso María Mamérita Mestanza Chávez vs Perú, petición 12.191, en el Informe $\mathrm{N}^{\circ} 71 / 03$, del 10 de octubre de 2003, se declaró responsable al Estado peruano al someter, de manera forzada, a un procedimiento quirúrgico de esterilización, que finalmente ocasionó la muerte de la señora Mestanza Chávez, que representó uno más entre un número significativo de casos de mujeres afectadas por la aplicación de una política gubernamental de carácter ma- 
sivo, compulsivo y sistemático que enfatizó la esterilización como método para modificar rápidamente el comportamiento reproductivo de la población, especialmente de mujeres pobres, indígenas y de zonas rurales.

De igual forma, la Corte Interamericana de Derechos Humanos también resaltó la vinculación de la discriminación y la violencia contra las mujeres, en especial las que se encuentran en una situación de vulnerabilidad por pertenecer a una comunidad indígena. En el Caso Valentina Rosendo Cantú y Otra vs México, a través de la sentencia del 31 de agosto de 2010, determinó la responsabilidad del Estado mexicano de no actuar con la debida diligencia por la violación de la Rosendo Cantú, mujer indígena Me'phaa, quien fue violada sexualmente por militares en las cercanías de su hogar, pero la investigación fue archivada en el fuero penal militar, no pudiéndose identificar ni sancionar a los agresores. Asimismo, la Corte Interamericana resolvió el Caso Inés Fernández Ortega y Otros vs México, en la sentencia del 30 de agosto de 2010, mediante el cual encontró responsabilidad del Estado, debido a que la justicia de su país no procedió a investigar ni sancionar a los agentes militares que violaron sexualmente a Inés Fernández, mujer indígena también Me'phaa, no actuando con la debida diligencia en el procesamiento de la denuncia de este delito.

Debo resaltar que la Corte Interamericana realizó la calificación jurídica de la violencia sexual como tortura, cuando esta es realizada por agentes del Estado. Este estándar internacional lo podemos encontrar en el Caso Penal Miguel Castro Castro vs Perú, mediante la sentencia del 25 de noviembre de 2006, en el contexto las mujeres afectadas se encontradas privadas de su libertad; situación similar ocurrió en el Caso J. vs Perú, quien fue privada de su libertad de manera ilegal y arbitraria en condiciones inhumanas, en las oficinas del Estado, por la comisión de supuestos delitos de terrorismo, por 17 días, tiempo en el cual fue violada sexualmente. Estas situaciones, colocaron a ambas mujeres en una situación de vulnerabilidad.

Se debe recordar que el deber de debida diligencia tiene como fuente lo establecido en el artículo 8 de la Convención Americana de Derechos Humanos; específicamente, en lo señalado en el artículo 7.b de la Convención de Belém do Pará, que dispone que los Estados deben actuar con la debida diligencia para prevenir, investigar y sancionar la discriminación y la violencia contra la mujer, para prevenir, sancionar y erradicar dicha esta situación de vulneración de derechos fundamentales.

Esta obligación permite que los países garanticen la disponibilidad de mecanismos judiciales efectivos, adecuados e imparciales, ya había sido dispuesta por la Comisión Interamericana de Derechos Humanos, a través del emblemático Caso Ana, Beatriz y Celia González Pérez vs México, Informe N53/01, del 4 de abril de 2001, en el cual se determinó la responsabilidad internacional del Estado mexicano por la detención ilegal, violación y tortura por parte de agentes militares, en agravio de las hermanas Ana, Beatriz y Celia González Pérez, indígenas tzeltales, así como la posterior falta de investigación y reparación de tales hechos denunciados.

En ese sentido, se han establecido acciones para erradicar la discriminación contra las mujeres y los patrones estereotipados de comportamiento, que terminan, en muchos casos, en hechos de violencia en contra de la mujer. 


\subsubsection{Jurisprudencia europea}

La Corte Europea de Derechos Humanos, mediante el Caso Kontrova vs Eslovaquia, demanda $\mathrm{N}^{\circ} 7510 / 04$, en la sentencia del 31 de mayo de 2007, declaró la responsabilidad del Estado eslovaco cuando los agentes policiales ayudaron a retirar la denuncia penal que una mujer interpuso en contra de su esposo por haberla golpeado, cuando ella regresó a la comisaria acompañada del agresor. Poco después, en un acto de venganza, el marido asesinó a sus dos hijos. En esta causa vemos la inacción de la policía de continuar la denuncia frente a una evidente coacción por parte del hombre contra la mujer, al naturalizar los hechos de violencia de género.

Asimismo, la Corte Europea, a través del Caso Bevacqua y S. vs Bulgaria, demanda $\mathrm{N}^{\circ} 71127 / 01$, en la sentencia del 12 de junio de 2008, determinó que la violencia contra la mujer es un asunto público y no privado, debido a que es incompatible con las obligaciones de los países el no garantizar la protección de los derechos de las personas, y que las autoridades gubernamentales no intervengan en los asuntos de violencia doméstica. Por lo que cualquier denuncia debe continuar su procedimiento para investigar y sancionar al responsable de los actos de discriminación y de violencia contra la mujer y el grupo familiar.

\section{El delito de feminicidio}

\subsection{Regulación en los países latinoamericanos}

En América Latina se han regulado leyes que tipifican el femicidio o el feminicidio, según el país. Marcela Lagarde (2005) señala que:

El feminicidio es una ínfima parte visible de la violencia contra niñas y mujeres, sucede como culminación de una situación caracterizada por la violación reiterada y sistemática de los derechos humanos de las mujeres. Su común denominador es el género: niñas y mujeres son violentadas con crueldad por el solo hecho de ser mujeres y sólo en algunos casos son asesinadas como culminación de dicha violencia pública o privada.

El delito de femicidio se legisló por primera vez en Costa Rica, donde se publicó la Ley de Penalización de la Violencia Contra las Mujeres, Ley $\mathrm{N}^{\circ} 8589$, del 25 de abril de 2007, que en su artículo 21 disponía que se le impondrá pena de prisión de veinte a treinta y cinco años a quien dé muerte a una mujer con la que mantenga una relación de matrimonio, en unión de hecho declarada o no.

Asimismo, en Guatemala, mediante la Ley contra el femicidio y otras formas de violencia contra la Mujer, por el Decreto 22-2008, del 2 de mayo de 2008, definió al femicidio como la muerte violenta de una mujer, ocasionada en el contexto de las relaciones desiguales de poder entre hombres y mujeres, en ejercicio del poder de género en contra de las mujeres. Y, en su artículo 6 indica las circunstancias que configuran este delito, al señalar que se comete femicidio por: 
a. Haber pretendido infructuosamente establecer o restablecer una relación de pareja o de intimidad con la víctima.

b. Mantener en la época en que se perpetre el hecho, o haber mantenido con la víctima relaciones familiares, conyugales, de convivencia, de intimidad o noviazgo, amistad, compañerismo o relación laboral.

c. Como resultado de la reiterada manifestación de violencia en contra de la víctima.

d. Como resultado de ritos grupales usando o no armas de cualquier tipo.

e. En menosprecio del cuerpo de la víctima para satisfacción de instintos sexuales, o cometiendo actos de mutilación genital o cualquier otro tipo de mutilación.

f. Por misoginia.

g. Cuando el hecho se cometa en presencia de las hijas o hijos de la víctima.

h. Concurriendo cualquiera de las circunstancias de calificación contempladas en el artículo 132 del Código Penal.

La persona responsable de este delito será sancionada con pena de prisión de veinticinco a cincuenta años, y no podrá concedérsele la reducción de la pena por ningún motivo. Las personas procesadas por la comisión de este delito no podrán gozar de ninguna medida sustitutiva.

De igual forma, Chile, por medio de la Ley $\mathrm{N}^{\circ} 20480$, del 14 de diciembre de 2010, reformó el artículo 390 del Código Penal; y Nicaragua, a través de la Ley Integral contra la violencia hacia las Mujeres, Ley $\mathrm{N}^{\circ} 779$, del 20 de febrero de 2012.

Mientras que el delito de feminicidio se reguló en El Salvador, el cual promulgó la Ley Especial Integral para una Vida Libre de Violencia para las Mujeres, Ley N520, del 25 de noviembre de 2010; y México, mediante la reforma del artículo 325 del Código Penal Federal, el 13 de junio de 2012.

\subsection{Regulación en el Perú}

La Defensoría del Pueblo (2010; p.57), a través del Informe $\mathrm{N}^{\circ} 04-2010 / D P-A D M$, señaló que:

En los últimos años, el derecho penal ha sufrido cambios importantes en materia de protección de derechos humanos de las mujeres. Aunque muchos de ellos aún son formales, no se puede negar que ha evolucionado desde la absoluta permisividad de los actos de violencia contra las mujeres hacia el reconocimiento parcial de esta problemática; desde la consideración de los delitos sexuales como acciones de índole privada hacia el reconocimiento de éstos, pasibles de persecución pública; desde la atenuación de los homicidios de la cónyuge si era encontrada en adulterio hacia las propuestas de tipificación específica del feminicidio.

La legislación peruana recogió la figura jurídica del feminicidio, a través de la modificación del artículo 107 del Código Penal, por la Ley N29819, del 27 de diciembre de 2011, como parricidio/feminicidio. Sin embargo, a mitad del año 2013, se publicó la Ley N30068, 
que incorpora el artículo 108-B en el Código Penal, constituyéndose el tipo penal del feminicidio, como la muerte de la mujer por su condición de género, como un delito autónomo.

Actualmente, este artículo ha sido modificado en varias ocasiones, siendo la última por la Ley $\mathrm{N}^{\circ} 30819$, del 13 de julio de 2018, cuyo texto es el siguiente:

Será reprimido con pena privativa de libertad no menor de veinte años el que mata a una mujer por su condición de tal, en cualquiera de los siguientes contextos:

1. Violencia familiar.

2. Coacción, hostigamiento o acoso sexual.

3. Abuso de poder, confianza o de cualquier otra posición o relación que le confiera autoridad al agente.

4. Cualquier forma de discriminación contra la mujer, independientemente de que exista o haya existido una relación conyugal o de convivencia con el agente.

La pena privativa de libertad será no menor de treinta años cuando concurra cualquiera de las siguientes circunstancias agravantes.

1. Si la víctima era menor de edad o adulta mayor.

2. Si la víctima se encontraba en estado de gestación.

3. Si la víctima se encontraba bajo cuidado o responsabilidad del agente.

4. Si la víctima fue sometida previamente a violación sexual o actos de mutilación.

5. Si al momento de cometerse el delito, la víctima tiene cualquier tipo de discapacidad.

6. Si la víctima fue sometida para fines de trata de personas o cualquier tipo de explotación humana.

7. Cuando hubiera concurrido cualquiera de las circunstancias agravantes establecidas en el artículo 108.

8. Si, en el momento de cometerse el delito, estuviera presente cualquier niña, niño o adolescente.

9. Si el agente actúa en estado de ebriedad, con presencia de alcohol en la sangre en proporción mayor de 0.25 gramos-litro, o bajo efecto de drogas tóxicas, estupefacientes, sustancias psicotrópicas o sintéticas.

La pena será de cadena perpetua cuando concurran dos o más circunstancias agravantes.

En todas las circunstancias previstas en el presente artículo, se impondrá la pena de inhabilitación conforme a los numerales 5 y 11 del artículo 36 del presente Código y los artículos 75 y 77 del Código de los Niños y Adolescentes, según corresponda.

Wilson Hernández (2018; p.47) expone que hubo cambios significativos en la norma sobre el feminicidio, la cual, hasta antes del 2013, no era considerada como un delito autónomo, sino que sus supuestos se encontraban inmersos en otro delito, el parricidio, como el asesinato del cónyuge o de quien sostenga una relación análoga. No sería hasta después del 2013, que el feminicidio se convertiría en un delito autónomo, incluyendo en su concepto a los feminicidios no íntimos. 


\subsubsection{Diferencia del delito de feminicidio con el delito por emoción violenta}

Hace años, no se contaba con la figura del feminicidio, por lo que la muerte de las mujeres en manos de los hombres de su entorno afectivo, era disfrazada como el delito de homicidio por emoción violenta, dispuesto en el artículo 109 del Código Penal. Ello llevaba al feminicida a darle una connotación reactiva y exculpatoria frente a un suceso fatal, en el cual se culpabilizaba a la mujer, llegándose incluso a la absolución del asesino.

Para ello, se dejaba de lado ciertos criterios para determinar aquella "emoción violenta", al no considerarse el intervalo de tiempo entre la provocación y el hecho, que no puede ser un largo espacio temporal; el medio empleado para la comisión del delito; el temperamento del sujeto; y el conocimiento previo de la situación por parte del autor, debido a que la emoción violenta supone la aparición súbita e inesperada de una situación.

Durante muchos años, los hechos de feminicidio fueron calificados como delitos de "crimen pasional", causados por emoción violenta; resultando una válvula legal de escape e impunidad.

Sin embargo, se advierte que esto ya quedó en el pasado y el Poder Judicial no da marcha atrás frente a estas situaciones, que se evidencian como la forma extrema de la violencia de género.

Cabe resaltar que, en una reciente sentencia de la Corte Interamericana de Derechos Humanos, mediante el Caso Gutiérrez Hernández y Otros vs Guatemala, en la sentencia del 24 de agosto de 2017, se advierte que el concepto de "crimen pasional" es parte de un estereotipo que justifica la violencia contra la mujer, en las causas judiciales de feminicidio.

\subsubsection{Contextos en los que se produce el feminicidio}

El Acuerdo Plenario $\mathrm{N}^{\circ} 001-2016 / \mathrm{CJ}-116$ desarrolla los contextos en los que se produce este delito, indicando que:

52. El feminicidio es un acto concreto realizado por un hombre suprimiendo la vida de una mujer. Es ciertamente el reflejo de un conjunto de condiciones estructurales, que van más allá de la conducta homicida del sujeto activo, y que expresan una relación asimétrica de poder entre el hombre y la mujer, en desmedro de esta última.

53. Si bien por exigencias de un derecho penal de acto, se debe castigar únicamente las manifestaciones concretas del autor, en contra de la norma penal que prohíbe atentar contra la vida de la mujer, el legislador ha considerado necesario ubicar el ataque a la vida de la mujer, en un contexto situacional determinado. De esta manera ha estimado que la violencia desencadenante de la muerte de la víctima, no es un episodio, no es una eventualidad, sino el lamentable resultado de un conjunto de circunstancias precedentes, y parte de construcciones culturales que han alimentado el resultado fatal. Por imperativos del mandato de determinación, es menester delimitar cada uno de ellos, en concordancia claro está con el ordenamiento jurídico en general. 
En este contexto, la violencia de género y la ocurrencia de feminicidios responden a la frustración de los hombres por la imposibilidad de controlar a las mujeres. Los agresores construyen un discurso justificante de la violencia y describen los "móviles" del crimen, culpabilizando a las propias mujeres, por la falta de cumplimiento de sus roles; por lo que se sienten afectados en su condición de varones.

Dichos discursos están plagados de elementos de discriminación, que transmiten su sentido de propiedad sobre las mujeres; con la intensión de doblegar su voluntad y autonomía respecto a las decisiones que pretendieron tomar sobre su propia vida, cuerpo, sexualidad y relaciones.

En este sentido, el feminicidio debe ser entendido como el acto culminante de un proceso previo de sojuzgamiento extremo a la víctima, que lo convierte también en un delito pluriofensivo, en sus modalidades agravadas, considerando la edad de la mujer, si estaba gestando, la mujer se encontraba bajo el cuidado o responsabilidad del agente, la violación sexual previa, el abuso de la discapacidad, la trata de personas u otros actos de explotación, la presencia de los hijos durante el feminicidio, y el concurso con agravantes del homicidio calificado, como la ferocidad, codicia, lucro, placer, para facilitar u ocultar otro delito, con gran crueldad o alevosía, por fuego, explosión o cualquier medio capaz de poner en peligro la vida, o salud de otras personas.

También, se debe considerar la situación legal de las niñas, niños y adolescentes que quedan "huérfanos" por la muerte de la madre, cuando el feminicida es el padre, quien, en muchos casos, aún continúa ejerciendo la patria potestad durante la tramitación del proceso judicial. Incluso, cuando el feminicida es sentenciado a una pena privativa de libertad y pierde la patria potestad, es la familia o las personas del vínculo social paterno quienes obligan a las hijas o hijos a visitar a su progenitor en las cárceles; situación que claramente vulnera sus derechos, como su integridad personal y de vivir en un ambiente libre de violencia, reconocidos en la Convención sobre los Derechos del Niño de las Naciones Unidas del 20 de noviembre de 1989.

\subsubsection{Eliminación de beneficios procesales para los feminicidas}

El 27 de agosto de 2018, se publicó el Decreto Legislativo º1382, que modificó los artículos 161 y 471 del Código Procesal Penal, promulgado por el Decreto Legislativo $\mathrm{N}^{\circ} 957$, el cual tuvo por objeto eliminar los efectos de la confesión sincera en los delitos de feminicidio y contra la libertad sexual, así como los efectos de la terminación anticipada en el delito de feminicidio. La aplicación de tales mecanismos procesales permitía reducir considerablemente la sanción a imponerse, flexibilizándola de tal manera que no solo era una suerte de premio al asesino, sino que también la respuesta estatal era de minimizar estos hechos de violencia frente a la sociedad.

De igual manera, este delito implica la suspensión y la pérdida de la patria potestad del feminicida, conforme con los artículos 75 y 77 del Código de los Niños y Adolescentes, según corresponda al momento procesal. 


\subsection{Jurisprudencia interamericana}

La Comisión Interamericana de Derechos Humanos, en los casos de tentativa de feminicidio y de feminicidio, ha emitido pronunciamientos emblemáticos, como en el Caso María Da Penha Maia Fernandes vs Brasil, Caso 12.051 a través del Informe N54/01, del 16 de abril de 2001, en el cual se presentan por primera vez los alcances del principio de la debida diligencia, en el marco de la Convención Americana y la Convención de Belém do Pará.

En este caso se alegó la tolerancia por parte de la República Federativa de Brasil, sobre la violencia en perjuicio de Maria da Penha Maia Fernandes, perpetrada en por Marco Antônio Heredia Viveiros, durante años de su convivencia matrimonial, que culminó en una tentativa de homicidio y nuevas agresiones en 1983. Desde esa fecha, como producto de esas agresiones, Maria da Penha padece de paraplejia irreversible y otras dolencias. Se denunció la tolerancia estatal por no haber tomado por más de quince años medidas efectivas necesarias para procesar y penar al agresor, pese a las denuncias efectuadas.

Esta causa generó todo un movimiento para la defensa de los derechos de las mujeres en los distintos países de la región, que terminó con la aprobación de la Ley N¹1.340/2016 contra la violencia doméstica en Brasil.

Igualmente, entre los fallos de la Corte Interamericana de Derechos Humanos, debemos destacar el Caso González y Otras (Campo Algodonero) vs México, en la sentencia del 16 de noviembre de 2009, que evidenció los atroces crímenes de violencia sexual y asesinato de 3 mujeres, incluidas menores de edad, en la ciudad de Juárez, lugar donde además, asesinaban mujeres sin límites y con total impunidad, dado el machismo discordante y la violencia de género que caracteriza a dicha ciudad, en la que también proliferó un aumento de homicidios de mujeres realizada por organizaciones criminales.

En este caso la Corte Interamericana determinó la responsabilidad internacional del Estado mexicano por no actuar con la debida diligencia en las investigaciones y sanción de los responsables, a quienes nunca se llegaron a encontrar, pese a que en dicha zona se conocía que las mujeres jóvenes se encontraban en situación de vulnerabilidad.

De otro lado, en el Caso Masacre de las Dos Erres vs Guatemala, a través de la sentencia del 24 de noviembre de 2009, la Corte Interamericana responsabilizó al Estado guatemalteco por la omisión de la debida diligencia por la tortura, violación sexual y asesinato, entre otros actos en perjuicio de numerosas personas habitantes del parcelamiento de Las Erres, entre ellas mujeres y niñas, por parte de agentes militares.

\subsection{Jurisprudencia nacional}

Para efectos de este trabajo se analizó algunas Ejecutorias dictadas por las Salas Penal Permanente y Transitorias de la Corte Suprema de Justicia.

Es este sentido, es importante destacar la Casación Nº997-2017-Arequipa, del 10 de mayo de 2018, emitida por la Sala Penal Permanente, sobre un caso de feminicidio, en el cual el encausado asesinó a una adolescente de quince años de iniciales Y.P.M.G., cuando 
intentó violarla sexualmente luego de ingerir bebidas alcohólicas con ella horas antes. El feminicida argumentó que los hechos no configuraban este delito, sino de homicidio simple, previsto en el artículo 106 del Código Penal, y que, además, no se aplicó la eximente imperfecta regulada en el artículo 21.1 del Código Penal porque actuó bajo los efectos del alcohol ingerido.

La Sala Penal aplicó el Acuerdo Plenario $N^{\circ} 001-2016 / C J-116$, y analizó el contexto situacional en el que el acto feminicida se produce, como que previamente hubieron hechos de hostigamiento sexual y que el imputado mató a la agraviada cuando ella se encontraba en una situación de vulnerabilidad, debido a que ella se encontraba ebria y estaba dormida en su camioneta, por lo que éste aprovechó que su contextura física era inferior a la suya, que estaban solos en horas de madrugada en una playa, que imposibilitaba a la víctima de resistirse a la violación sexual; sin embargo, en el forcejeo él tomó una piedra y golpeó a la adolescente, causándole la muerte. En ese sentido, por los hechos sucedidos y las notas características del tipo penal de feminicidio, plenamente cumplidos en el presente caso, se tiene que el encausado cometió el referido delito.

En otro caso, la Sala Penal Permanente de la Corte Suprema, a través del Recurso de Nulidad $N^{\circ} 2034$-2015-Apurimac, del 13 de septiembre de 2016, ratificó la pena de 25 años de cárcel por el delito de feminicidio, debido al análisis que realizó sobre el contexto mediante el cual se cometió el crimen. El imputado y la victima convivieron como pareja por más de ocho años y procrearon dos hijos menores de edad, pero por los constantes conflictos y maltratos por parte del acusado, decidieron separarse, siendo el padre quien se quedó con la custodia de los niños. Una noche, luego de una discusión en una discoteca, donde el imputado hizo salir a la víctima, con golpes la condujo a su taller de trabajo, donde le propuso mantener relaciones sexuales, pero ante la negativa, la violó sexualmente, para luego, con la intención dolosa de matarla, le roció gasolina a todo su cuerpo y le prendió fuego, muriendo la mujer a los pocos días del hecho en un hospital. Es decir, se probó que el acusado generó un riesgo penalmente relevante para la vida de la víctima, al llevarla a su taller, lugar donde el feminicida estaba en control del espacio y la agraviada no podía oponerse a su fuerza, y en el cual manipulaba gasolina y fuego que utilizó para quemarla hasta producirle la muerte, en un acto de desprecio por su vida e impotencia, porque le niega la conducta dependiente que el agresor quería.

Sin embargo, se debe resaltar que en esta sentencia no se señala en sus disposiciones sobre la condición y la custodia de los hijos que quedaban huérfanos de madre, por lo que se advierte que esto debe ser revertido para garantizar su protección. Como sucede en muchas otras causas judiciales para hacer posible el seguimiento de las medidas de protección previstas en el Decreto Legislativo $\mathrm{N}^{\circ} 1297$ para la protección de las niñas, niños y adolescentes en desprotección familiar, y su respectivo Reglamento, aprobado por el Decreto Supremo Nº01-2018-MIMP; así como la suspensión o la pérdida de la patria potestad del progenitor feminicida.

En otra sentencia, se encuentra que la Sala Penal Transitoria de la Corte Suprema, mediante el Recurso de Nulidad N³426-2014-Lima, del 21 de julio de 2016, declaró la nulidad de la sentencia emitida por la sala superior, que solamente condenó al feminicida 
a 20 años de prisión, cuando le correspondería una sanción mayor a 25 años. Esto debido a que se observó que el tribunal superior emitió sentencia en un proceso de terminación anticipada, por la renuncia del acusado a la actuación probatoria, haber realizado una supuesta "confesión sincera" y por la aceptación de la tesis incriminatoria del fiscal, acreditándose el hecho delictivo y su responsabilidad penal, que llevó a una reducción de la condena; lo que resultaría inviable a partir de la nueva normativa que prohíbe la aplicación de estos mecanismos procesales.

Así pues, la Sala Suprema determinó que, si bien se realizó una supuesta "confesión sincera", por la naturaleza del delito, no es posible considerarla como tal. Más aún que, en los hechos, el feminicida, luego de una discusión con su pareja, la asfixió hasta causarle la muerte y luego cercenó su cuerpo en partes, los cuales esparció dentro de costales y el resto lo enterró en un asentamiento humano. Manifestándose así, la crueldad del crimen.

En otra causa judicial, la Sala Penal Transitoria de la Corte Suprema, a través del Recurso de Nulidad $N^{\circ} 1257-2015$-Lima, del 19 de julio de 2016, reafirmó la imposición de 25 años de pena privativa de libertad y fijó, como reparación civil, el monto de 20 mil soles a un feminicida, quien cuestionó la sentencia impuesta al señalar que no había quedado demostrado la existencia de una relación sentimental o convivencial entre él y la mujer asesinada, y que el cometió el crimen actuando bajo una emoción violenta, por lo que no se configuraría el delito feminicidio.

Al respecto, la Sala Suprema consideró que, si se estableció el feminicidio debido a que, el día del crimen, el imputado y la víctima se dirigieron a un hostal para mantener relaciones sexuales, pero luego discutieron por motivo del embarazo de la agraviada, por lo que el acusado utilizó la fuerza física para coaccionarla y hostigarla con el fin de que aborte, llegando a ahorcarla y matarla.

En el primer cuestionamiento, la Sala Penal Transitoria señaló que el tipo penal no exige que entre la víctima y el victimario exista o haya existido una relación sentimental o de convivencia, y precisó que el feminicidio es la manifestación más extrema de violencia perpetrada contra la mujer, que tiene como característica un sustrato misógino o sexista. Asimismo, que se diferencia del homicidio concretamente por las motivaciones, en el feminicidio el agente desvaloriza la condición de mujer asentado en criterios errados de superioridad y autorización para ejercer sobre ésta actos de control y castigo; en el caso bajo análisis, existió un hostigamiento previo contra la mujer por su negativa de abortar, lo que el feminicida sostuvo como justificación de su crimen.

Además, respecto al segundo cuestionamiento, no es posible aplicar la figura de homicidio por emoción violenta, en tanto del relato fáctico del inculpado se advierte que no existió una situación objetiva y repentina que pueda encausarse dentro de tal supuesto.

Cabe resaltar que es necesario que las juezas y jueces, además de las disposiciones contenidas en nuestra legislación, observen lo señalado por los tratados e instrumentos internacionales de derechos humanos a los cuales el Perú ha ratificado, y que forman parte de la norma interna. Especialmente, también deben considerar la jurisprudencia emitida por los máximos órganos de justicia a nivel regional, y analizarlos al momento de emitir sus sentencias. 


\section{Conclusiones}

A pesar de los avances normativos y de políticas públicas, la violencia de género contra las mujeres en el Perú continúa y se ha incrementado en los últimos años.

La estructura social machista del país invisibiliza, naturaliza e incluso justifica la violencia contra la mujer; lo que se observa reflejado en la ocurrencia de un gran número de feminicidios.

Se debe recordar que las juezas y los jueces ya no pueden aplicar beneficios procesales a los feminicidas, respecto a su supuesta confesión y arrepentimiento, pues hay una prohibición legal expresa para los casos de feminicidio.

Se debe hacer frente a la impunidad, ya que solo ha de retroalimentar el conjunto de roles de género que subordinan a las mujeres, y en ese sentido, afianza y mantiene vigente una estructura discriminatoria de la sociedad que perpetúa la violencia.

Por lo demás, debe plantearse la derogación de la figura del homicidio por emoción violenta de la legislación penal peruana, para acabar con mecanismos de escape legal de los feminicidas.

En este contexto, estos son los avances sobre los cuales el Poder Judicial no va a retroceder, sino que seguirá adelante para la prevención sanción y erradicación del feminicidio, así como la protección de los derechos fundamentales de las mujeres y de la niñez, aplicando la perspectiva de género y de derechos humanos.

Finalmente, debo señalar que las políticas institucionales de género y los criterios jurisdiccionales deben de aplicarse y difundirse. El Perú debe ir a la vanguardia para que la justicia con igualdad no sea una declaración o teoría sino una realidad accesible y verdadera, como en el resto de los países de la región iberoamericana.

\section{Bibliografía}

CUMBRE JUDICIAL IBEROAMERICANA (2014) Protocolo Iberoamericano de actuación judicial para mejorar el acceso a la justicia de personas discapacidad, migrantes, niñas, niños, adolescentes, comunidades y pueblos indígenas. Recuperado de http://www. cumbrejudicial.org/productos-y-resultados/productos-axiologicos/item/38-protocolo-de-acceso-a-la-justicia-para-personas-y-grupos-vulnerables

CUMBRE JUDICIAL IBEROAMERICANA (2014) Protocolo de Actuación Judicial para casos de violencia de género contra las mujeres. Recuperado de http://www.cumbrejudicial.org/productos-y-resultados/productos-axiologicos/item/38-protocolo-deacceso-a-la-justicia-para-personas-y-grupos-vulnerables

CUMBRE JUDICIAL IBEROAMERICANA (2008) Reglas de Brasilia sobre Acceso a la Justicia de las Personas en Condición de Vulnerabilidad. Recuperado de https://www.acnur. org/fileadmin/Documentos/BDL/2009/7037.pdf

COMISIÓN INTERAMERICANA DE DERECHOS HUMANOS (2015) Estándares jurídicos vinculados a la igualdad de género y a los derechos de las mujeres en el sistema in- 
teramericano de derechos humanos: desarrollo y aplicación. Recuperado de http:// www.oas.org/es/cidh/informes/pdfs/EstandaresJuridicos.pdf

COOK, REBECCA y CUSACK, SIMONE. (2010) Estereotipos de Género. Perspectivas Legales Transnacionales. Pennsylvania, Estados Unidos: Universidad de Pennsylvania.

Defensoría del Pueblo (2010) Feminicidio en el Perú: Estudio de expedientes judiciales. Recuperado de https://www.defensoria.gob.pe/wp-content/uploads/2018/05/informe-feminicidio.pdf

GONZÁLEZ GAVALDÓN, BLANCA. (1999) Los estereotipos como factor de socialización en el género. Comunicar (12), pp.79-88.

HERNÁNDEZ, WILSON; RAGUZ, MARÍA y OTROS (2018) Feminicidio: Determinantes y evaluación del riesgo. Recuperado de https://www.cies.org.pe/sites/default/files/ investigaciones/ul_-_feminicidios_determinantes_y_evaluacion_de_riesgo.pdf

HUAITA ALEGRE, MARCELA (2009) Perspectiva de género, teorías y alcance del concepto. En Entre la teoría y la práctica: nuevas perspectivas sobre los derechos humanos de la mujer, pp.17-24. Lima, Perú: Instituto de Democracia y Derechos Humanos de la Pontificia Universidad Católica del Perú. Recuperado de: https://idehpucp.pucp.edu. pe/images/publicaciones/nuevas_perspectivas_sobre_los_ddhh_de_la_mujer.pdf

JIMÉNEZ MARTÍNEZ, KATIA MIGUELINA (22 de noviembre de 2017) Ponencia: Juzgar con perspectiva de género. Una buena práctica para combatir la violencia contra la mujer e intrafamiliar. Congreso Mejores Prácticas en la lucha contra la Violencia de Género llevado a cabo en Hotel Real Intercontinental, Santo Domingo, República Dominicana. LAGARDE, MARCELA (2005) ¿A qué llamamos feminicidio? Por la Vida y la Libertad de las Mujeres. 1er Informe Sustantivo de actividades 14 de abril 2004 al 14 abril 2005, Comisión Especial para Conocer y dar seguimiento a las Investigaciones Relacionadas con los Feminicidios en la República Mexicana y a la Procuración de Justicia Vinculada. MEJÍA GUERRERO, LUZ PATRICIA. (2012) La Comisión Interamericana de Mujeres y la Convención de Belém do Pará. Impacto en el Sistema Interamericano de Derechos Humanos. Revista IIDH (56), pp.189-2013.

MINISTERIO DE LA MUJER Y POBLACIONES VULNERABLES (2019) Feminicidio y Tentativas según región de ocurrencia 2019. Recuperado de https://www.mimp.gob.pe/ contigo/contenidos/pncontigo-articulos.php?codigo=39

MINISTERIO DE LA MUJER Y POBLACIONES VULNERABLES (2018a) Personas Afectadas por VFS atendidas en los CEM según tipo de violencia, edad y sexo 2018. Recuperado de https://www.mimp.gob.pe/contigo/contenidos/pncontigo-articulos. php?codigo $=36$

MINISTERIO DE LA MUJER Y POBLACIONES VULNERABLES (2018b) Feminicidio y Tentativas según región de ocurrencia 2018. Recuperado de https://www.mimp.gob.pe/ contigo/contenidos/pncontigo-articulos.php?codigo=39

MINISTERIO DE LA MUJER Y POBLACIONES VULNERABLES (2017a) Personas Afectadas por VFS atendidas en los CEM según tipo de violencia, edad y sexo 2017. Recuperado de https://www.mimp.gob.pe/contigo/contenidos/pncontigo-articulos. php? $\operatorname{codigo}=36$ 
MINISTERIO DE LA MUJER Y POBLACIONES VULNERABLES (2017b) Feminicidio y Tentativas según región de ocurrencia 2017. Recuperado de https://www.mimp.gob.pe/ contigo/contenidos/pncontigo-articulos.php?codigo $=39$

MINISTERIO DE LA MUJER Y POBLACIONES VULNERABLES (2016) Ley 30364, Ley para prevenir, sancionar y erradicar la violencia contra las mujeres y los integrantes del grupo familiar. Recuperado de https://www.mimp.gob.pe/webs/mimp/ley30364/ sobre-ley-30364.php

MINISTERIO DE LA MUJER Y POBLACIONES VULNERABLES (2015) Convención de Belém do Pará. Recuperado de https://www.mimp.gob.pe/mesecvi/convencion.php

NACIONES UNIDAS (1995) Informe de la Cuarta Conferencia Mundial sobre la Mujer de las Naciones Unidas. Beijing, 4 a 15 de septiembre de 1995.

RICO, NIEVES (1996) Violencia de Género: Un problema de Derechos Humanos. Santiago de Chile, Chile: Comisión Económica para América Latina y El Caribe (CEPAL).

SCOTT, JOAN (1986) El género: una categoría útil para el análisis histórico. En América Historical Review (91). 